\section{The differences of the oral hygiene status in patients with cleft lip and palate pre operative and post operative in Takalar Regency}

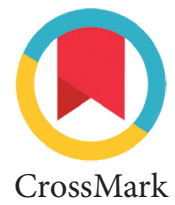

\author{
Muhammad I. Rasul, ${ }^{1,2 *}$ Andi Tajrin, ${ }^{2}$ Muhammad Ruslin, ${ }^{2}$ Abul Fauzi, ${ }^{2}$ \\ Kumiko Fujiwara, ${ }^{1}$ Makoto Noguchi, ${ }^{1}$ Sitti NW. Al-Bashir ${ }^{2}$
}

\title{
Abstract
}

Objective: This study aims to determine the difference in oral hygiene status in patients with cleft lip and palate pre operative and post operative in takalar regency. The sample in this study were patients with cleft lip and palate preoperative and postoperative with a total sample of 20 people consisting of 10 people for the preoperative group and 10 people for the postoperative group.

Material and Methods: This study is observational analytic and the design of this study is Cross Sectional Study. Determination of samples was done by quota sampling. Assessment of oral hygiene status was obtained from OHI-S scores. The data obtained were tested with chisquare test and t-test by SPSS.

Results: In the group of patients with cleft lip and palate preoperative had an average oral hygiene status of 2.69 while the postoperative group was 2.04 with $p$-value of 0.062 (>0.05).

Conclusion: There was no difference in the status of oral hygiene in patients with cleft lip and palate preoperative and postoperative in Takalar regency.
${ }^{1}$ Department of Oral and Maxillofacial Surgery, Medical Faculty, Toyama University, Toyama Shi, Japan ${ }^{2}$ Department of Oral and Maxillofacial Surgery, Faculty of Dentistry, Hasanuddin University, Makassar, Indonesia
${ }^{*}$ Correspondence to:

Muhammad I. Rasul, Departemen of Oral and Maxillofacial Surgery,

Medical Faculty, Toyama University,

Toyama Shi, Japan

irfanrasul82@gmail.com

Received: 6 January 2020

Revised: 10 March 2020

Accepted: 15 July 2020

Available Online: 1 December 2020

Keywords : Cleft lip and palate, Oral hygiene

Cite this Article: Rasul MI, Tajin A, Ruslin M, Fauzi A, Fujiwara K, Noguchi M, Al-Bashir SNW. 2020. The differences of the oral hygiene status in patients with cleft lip and palate pre operative and post operative in Takalar Regency. Journal of Dentomaxillofacial Science 5(3): 162-167. D0I: 10.15562/jdmfs.v5i3.1023

\section{Introduction}

Cleft lip and palate is the most common birth defects which found in the world that occurs in the craniofacial region. This rudiment is characterized by a spilt condition in the upper lip which up to the gum, jaw and palate. This occurs as a result of embryological abnormalities in the development of facial structures since the fourth week of pregnancy (first trimester). ${ }^{1}$

International data recorded in the 2002 to 2006 period, the incidence of cleft lip on average there were 8 per 10,000 births in the world. in Indonesia, The results of the 2013 Basic Health Research data shows the national prevalence of cleft lip and palate is $0.08 \%$, of which $0.9 \%$ is in the Province of South Sulawesi and for District of Takalar is $0.03 \%$. Based on the data of the Makassar Celebes Cleft Center Foundation, also obtained data on total sufferers of the lips and palates from August 2018 to March 2019 who have been operated 112 people and not yet operated on as many 25 people. ${ }^{1,2}$

One of the problems that can be caused by cleft lip and palate both preoperatively and postoperatively is a problem in oral hygiene. This can be caused by the presence of anatomic areas that are split, teeth that are not aligned, there is hypoplastic defects and scar tissue used in surgery so that it will be difficult to maintain oral and dental hygiene to be less optimal. ${ }^{3}$ This also related to educational status and economic status. The high level of education will make it easier for someone or the public to implant information and applying it in their daily and lifestyles, especially in terms of health including oral health or oral hygiene which is part of the health of the body that cannot be connected with one another, the cause of oral health or oral hygiene will also affect overall health. Likewise, people with high economic capacity will have no difficulties in meeting their basic need, so it will be easy to provide health services for their families. The economic condition of the family determines parents purchasing power over protective factors such as toothbrushes, fluoride toothpaste and the ability to come to the dentist. ${ }^{4}$

\section{Material and Methods}

This research is a analytic observational study using a cross sectional study design. This research is conducted in district Takalar in August 2019. The sample on this study was the patients with cleft lip and palate before surgery and postoperatively with a using quota sampling, which is a sampling technique that is not mixed with the amount agreed by the researchers. 
Oral hygiene status ranking is obtained from Oral Hygiene Index-Simplified (OHI-S) scores. The tools and materials used consist of OHI-S assessment sheets, handscoens, mask, mirror, sonde, nierbeken, pinset, glass, water, alcohol 70\%, povidone iodine, disclosing solution and cotton pellets. Data obtained from the results of the examination will be quoted with the chi-square test and t-test through SPSS.

\section{Results}

This research was conducted in district of Takalar on August 2019 with a total sample of 20 people consisting of 10 people for the preoperative group and 10 people for the postoperative group. Data from the results of the study are presented using the frequency distribution table as follows :

Data on the table 1 shows the age group of respondents in patients with cleft lip and palate pre operative is mostly old age (40\%), while in patients with cleft lip and palate post operative most children age (30\%) and old age (30\%). Based on gender in patients with cleft lip and palate pre operative the results obtained by male $(60 \%)$ more than female (40\%), while for patients with cleft lip and palate post operative female (60\%) more many are male (40\%). At the level of education that shows the patients with cleft lip and palate pre operative the most is the result of middle school $(30 \%)$ and high school (30\%), while in patients with cleft lip and palate post operative are the most high school (50\%). Based on the economic status of respondents in patients with cleft lip and palate pre operative, the results obtained most are high economic groups $(60 \%)$, while in patients with cleft lip and palate post operative is the most medium economic group (50\%).

Table 2 shows the status of oral hygiene in the groups of patients with cleft lip and palate pre operative each of 5 respondents $(50 \%)$ with fair and poor oral hygiene status, while in the group of patients with cleft lip and palate post operative 8 respondents (80\%) had fair oral hygiene status.

Table 3 shows the age group of respondents in patients with cleft lip and palate pre operative for the category of good oral hygiene status there is 0 people for ages toddlers, children, adolescent, adults and old people. For the category of fair oral hygiene status there is 1 person toddler, 0 children, 2 adolescent, 0 adults, and 2 old people. For the category of poor oral hygiene status there is 1 toddler, 0 children, 0 adolescent, 2 adult and 2 old people. As for the value of testing using chi-square obtained p-value of $0.261>0.05$, which means there is no significant relation between age and oral hygiene status in patients with cleft lip and palate pre operatively. Based on gender in patients with cleft lip and palate pre operative for the category of good oral hygiene status there is 0 people for male and female. For the categories of fair oral hygiene status there is 2 male dan 3 female. For the categories of poor oral hygiene status there is 4 male and 1 female. As for the value of testing using chi-square obtained p-value of $0.197>0.05$, which means there is no significant relation between gender and oral hygiene status in patients with cleft lip and palate pre operatively. At the level of education that shows the patients with cleft lip and palate pre operative for the category of good oral hygiene status there is 0 people who do not have a diploma/have not graduated from elementary school, elementary school, middle school, high school, D1/D2/D3, and $\mathrm{D} 4 / \mathrm{S} 1 / \mathrm{S} 2 / \mathrm{S} 3$. For the categories of fair oral hygiene status there is 0 people who do not have a diploma/ have not graduated from elementary school, 0 elementary school, 2 middle school, 2 high school, 0 D1/D2/D3, and $1 \mathrm{D} 4 / \mathrm{S} 1 / \mathrm{S} 2 / \mathrm{S} 3$. For the categories of poor oral hygiene status there is 2 people who do not have a diploma/have not graduated from elementary school, 0 elementary school, 1 middle school, 1 high school, 0 D1/D2/D3, and 1 D4/S1/ $\mathrm{S} 2 / \mathrm{S} 3$. As for the value of testing using chi-square obtained p-value of $0.446>0.05$, which means there is no significant relation between level of education and oral hygiene status in patients with cleft lip and palate pre operatively. Based on the economic status of respondents in patients with cleft lip and palate pre operative for the category of good oral hygiene status there is 0 people with low economic group, medium economic group, high economic group and very high economic group. For the categories of fair oral hygiene status there is 1 people with low economic group, 0 people with medium economic group, 4 people with high economic group and 0 people with very high economic group. For the categories of poor oral hygiene status there is 1 people with low economic group, 2 people with medium economic group, 2 people with high economic group and 0 people with very high economic group. As for the value of testing using chi-square obtained p-value of $0.264>0.05$, which means there is no significant relation between economic status and oral hygiene status in patients with cleft lip and palate pre operatively.

Table 4 shows the age group of respondents in patients with cleft lip and palate post operative for the category of good oral hygiene status there is 0 toodlers, 0 children, 1 adolescent, 0 people for adults and old people. For the category of fair oral hygiene status there is 2 toodlers, 3 childrens, 0 adolescent, 1 adults, dan 2 old people. For the category of poor oral hygiene status there is 0 toodler, 0 children, 0 adolescent, 0 adult dan 1 old people. As for the 
value of testing using chi-square obtained p-value of $0.130>0.05$, which means there is no significant relation between age and oral hygiene status in patients with cleft lip and palate post operatively. Based on gender in patients with cleft lip and palate post operative for the category of good oral hygiene status there is 0 male and 1 female. For the categories of fair oral hygiene status there is 3 male dan 5 female. For the categories of poor oral hygiene status there is 1 male and 0 female. As for the value of testing using chi-square obtained p-value of $0.335>0.05$, which means there is no significant relation between gender and oral hygiene status in patients with cleft lip and palate post operatively. At the level of education that shows the patients with cleft lip and palate post operative for the category of good oral hygiene status there is 0 people who do not have a diploma/have not graduated from elementary school, 0 elementary school, 0 middle school, 1 high school, 0 D1/D2/D3, and 0 D4/S1/ $\mathrm{S} 2 / \mathrm{S} 3$. For the categories of fair oral hygiene status there is 0 people who do not have a diploma/have not graduated from elementary school, 0 elementary school, 1 middle school, 4 high school, 0 D1/ $\mathrm{D} 2 / \mathrm{D} 3$, and $3 \mathrm{D} 4 / \mathrm{S} 1 / \mathrm{S} 2 / \mathrm{S} 3$. For the categories of poor oral hygiene status there is 1 people who

\section{Table 1 Characteristic frequency distribution of patients with cleft lip and palate pre operative and post operative}

\begin{tabular}{|c|c|c|c|c|}
\hline \multirow[b]{2}{*}{ Characteristic } & \multicolumn{2}{|c|}{ Pre Operative } & \multicolumn{2}{|c|}{ Post Operative } \\
\hline & $\mathbf{n}$ & $\%$ & 2 & $\%$ \\
\hline \multicolumn{5}{|l|}{ Age } \\
\hline Toddler (0-5 years) & 2 & 20 & 3 & 20 \\
\hline Children (6-11 years old) & 0 & 0 & 1 & 30 \\
\hline Adolescent (12-17 years) & 2 & 20 & 1 & 10 \\
\hline Adult (18-40 years) & 2 & 20 & 3 & 10 \\
\hline Old (41-65 years old) & 4 & 40 & & 30 \\
\hline \multicolumn{5}{|l|}{ Gender } \\
\hline Male & 6 & 60 & 4 & 40 \\
\hline Female & 4 & 40 & 6 & 60 \\
\hline \multicolumn{5}{|l|}{ Level of Education } \\
\hline $\begin{array}{l}\text { Do not have a diploma/ha } \\
\text { elementary school }\end{array}$ & 2 & 20 & 1 & 10 \\
\hline Elementary School & 0 & 0 & 0 & 0 \\
\hline Middle School & 3 & 30 & 1 & 10 \\
\hline High School & 3 & 30 & 5 & 50 \\
\hline $\mathrm{D} 1 / \mathrm{D} 2 / \mathrm{D} 3$ & 0 & 0 & 0 & 0 \\
\hline $\mathrm{D} 4 / \mathrm{S} 1 / \mathrm{S} 2 / \mathrm{S} 3$ & 2 & 20 & 3 & 30 \\
\hline \multicolumn{5}{|l|}{ Economic Status } \\
\hline Low & 2 & 20 & 0 & 0 \\
\hline Medium & 2 & 20 & 5 & 50 \\
\hline High & 6 & 60 & 2 & 20 \\
\hline Very high & 0 & 0 & 3 & 30 \\
\hline
\end{tabular}

Table 2 Frequency distribution of oral hygiene status in patients with cleft lip and palate pre operative and post operative

\begin{tabular}{lccccc}
\hline & \multicolumn{2}{c}{ Pre Operative } & & \multicolumn{2}{c}{ Post Operative } \\
\cline { 2 - 5 } \cline { 4 - 5 } Oral Hygiene Status & $\mathbf{n}$ & $\%$ & $\mathbf{n}$ & 10 \\
\hline Good & 0 & 0 & 1 & 80 \\
Fair & 5 & 50 & 50 & 1 & 10 \\
Poor & 5 & 100 & 10 & 100 \\
Total & 10 & & & 10 \\
\hline
\end{tabular}


Table 3 Relation between age, gender, level of education and economic status with oral hygiene status in patient with cleft lip and palate pre operative

\begin{tabular}{|c|c|c|c|c|c|}
\hline \multirow[b]{2}{*}{ Variables } & \multirow[b]{2}{*}{ Sub-group } & \multicolumn{3}{|c|}{ Oral Hygiene Status } & \multirow[b]{2}{*}{ p-value } \\
\hline & & Good & Fair & Poor & \\
\hline \multirow[t]{5}{*}{ Age } & Toddler & 0 & 1 & 1 & \multirow{5}{*}{0.261} \\
\hline & Children & 0 & 0 & 0 & \\
\hline & Adolescent & 0 & 2 & 0 & \\
\hline & Adult & 0 & 0 & 2 & \\
\hline & Old & 0 & 2 & 2 & \\
\hline \multirow[t]{2}{*}{ Gender } & Male & 0 & 2 & 4 & \multirow{2}{*}{0.197} \\
\hline & Female & 0 & 3 & 1 & \\
\hline \multirow[t]{6}{*}{ Level of Education } & $\begin{array}{l}\text { Do not have a diploma/have not } \\
\text { graduated from elementary school }\end{array}$ & 0 & 0 & 2 & \multirow{6}{*}{0.446} \\
\hline & Elementary School & 0 & 0 & 0 & \\
\hline & Middle School & 0 & 2 & 1 & \\
\hline & High School & 0 & 2 & 1 & \\
\hline & $\mathrm{D} 1 / \mathrm{D} 2 / \mathrm{D} 3$ & 0 & 0 & 0 & \\
\hline & $\mathrm{D} 4 / \mathrm{S} 1 / \mathrm{S} 2 / \mathrm{S} 3$ & 0 & 1 & 1 & \\
\hline \multirow[t]{4}{*}{ Economic Status } & Low & 0 & 1 & 1 & \multirow{4}{*}{0.264} \\
\hline & Medium & 0 & 0 & 2 & \\
\hline & High & 0 & 4 & 2 & \\
\hline & Very High & 0 & 0 & 0 & \\
\hline
\end{tabular}

Table 4 Relation between age, gender, level of education and economic status with oral hygiene status in patient with cleft lip and palate post operative

\begin{tabular}{|c|c|c|c|c|c|}
\hline \multirow[b]{2}{*}{ Variables } & \multirow[b]{2}{*}{ Sub-group } & \multicolumn{3}{|c|}{ Oral Hygiene Status } & \multirow[b]{2}{*}{ p-value } \\
\hline & & Good & Fair & Poor & \\
\hline \multirow[t]{5}{*}{ Age } & Toddler & 0 & 2 & 0 & \multirow{5}{*}{0.130} \\
\hline & Children & 0 & 3 & 0 & \\
\hline & Adolescent & 1 & 0 & 0 & \\
\hline & Adult & 0 & 1 & 0 & \\
\hline & Old & 0 & 2 & 1 & \\
\hline \multirow[t]{2}{*}{ Gender } & Male & 0 & 3 & 1 & \multirow{2}{*}{0.335} \\
\hline & Female & 1 & 5 & 0 & \\
\hline \multirow[t]{6}{*}{ Level of Education } & $\begin{array}{l}\text { Do not have a diploma/have not } \\
\text { graduated from elementary school }\end{array}$ & 0 & 0 & 1 & \\
\hline & Elementary School & 0 & 0 & 0 & \multirow{5}{*}{0.088} \\
\hline & Middle School & 0 & 1 & 0 & \\
\hline & High School & 0 & 4 & 0 & \\
\hline & $\mathrm{D} 1 / \mathrm{D} 2 / \mathrm{D} 3$ & 0 & 0 & 0 & \\
\hline & $\mathrm{D} 4 / \mathrm{S} 1 / \mathrm{S} 2 / \mathrm{S} 3$ & 0 & 3 & 0 & \\
\hline \multirow[t]{4}{*}{ Economic Status } & Low & 0 & 0 & 0 & \multirow{4}{*}{0.143} \\
\hline & Medium & 0 & 5 & 0 & \\
\hline & High & 0 & 1 & 1 & \\
\hline & Very High & 1 & 2 & 0 & \\
\hline
\end{tabular}


Table 5 The results of analysis of differences of the oral hygiene status in patients with cleft lip and palate pre operative and post operative

\begin{tabular}{lcccc}
\hline Oral Hygiene Status & N & mean & SD & p-value \\
\hline Pre Operative & 10 & 2.69 & 0.74303 & 0.062 \\
Post Operative & 10 & 2.04 & 0.71833 & \\
\hline
\end{tabular}

do not have a diploma/have not graduated from elementary school, 0 elementary school, 0 middle school, 0 high school, 0 D1/D2/D3, and 0 D4/S1/ $\mathrm{S} 2 / \mathrm{S} 3$. As for the value of testing using chi-square obtained p-value of $0.088>0.05$, which means there is no significant relation between level of education and oral hygiene status in patients with cleft lip and palate post operatively. Based on the economic status of respondents in patients with cleft lip and palate post operative for the category of good oral hygiene status there is 0 people with low economic group, medium economic group, high economic group and 1 people with very high economic group. For the categories of fair oral hygiene status there is 0 people with low economic group, 5 people with medium economic group, 1 people with high economic group and 2 people with very high economic group. For the categories of poor oral hygiene status there is 0 people with low economic group, 0 people with medium economic group, 1 people with high economic group and 0 people with very high economic group. As for the value of testing using chi-square obtained p-value of $0.143>$ 0.05 , which means there is no significant relation between economic status and oral hygiene status in patients with cleft lip and palate post operatively.

Table 5 shows that results of oral hygiene status measurements in totally 20 respondents with cleft lip and palate each consists of 10 pre operative and 10 post operative, obtained an average oral hygiene status value for the preoperative group of 2.69 while the post-operative had an average of 2.04. As for the value of the test using the compare mean independent $\mathrm{t}$-test obtained $\mathrm{p}$-value of $0.062>0.05$ which means there is no significant difference through statistic testing between oral hygiene status in patients with cleft lip and palate pre operative and post operative.

\section{Discussion}

In this study, the sample was the patient with cleft lip and palate pre operative and post operative with a total sample of 20 people consisting of 10 people for the pre operative group and 10 people for the post operative group. This study aims to determine differences in oral hygiene status between patient with cleft lip and palate pre operative and post operative in Takalar Regency. Assessment of oral hygiene status was obtained from OHI-S scores.
Based on the results of the study obtained data that the patient with cleft lip and palate pre operative is mostly old age (40\%), while in patients with cleft lip and palate post operative most children age $(30 \%)$ and old age (30\%). Based on gender in patients with cleft lip and palate pre operative the results obtained by male $(60 \%)$ more than female (40\%), while for patients with cleft lip and palate post operative female $(60 \%)$ more many are male (40\%). At the level of education that shows the patients with cleft lip and palate pre operative the most is the result of middle school (30\%) and high school (30\%), while in patients with cleft lip and palate post operative are the most high school $(50 \%)$. Based on the economic status of respondents in patients with cleft lip and palate pre operative, the results obtained most are high economic groups $(60 \%)$, while in patients with cleft lip and palate post operative is the most medium economic group (50\%).

The status of oral hygiene in the groups of patients with cleft lip and palate pre operative each of 5 respondents $(50 \%)$ with fair and poor oral hygiene status, while in the group of patients with cleft lip and palate post operative 8 respondents $(80 \%)$ had fair oral hygiene status.

The results of the analysis shows that in the group of patient with cleft lip and palate pre operative based on the ages has a p-value $=0.261(>0.05)$ which means it does not have a statistically significant effect on oral hygiene status. The same result is shown in the group of patients with cleft lip and palate post operative based on the ages has a $\mathrm{p}$-value $=0.130(>0.05)$ which means it does not have a statistically significant effect on oral hygiene status. This is caused by the respondent ages that is variety used. ${ }^{5}$

The results of the analysis based shows that in the group of patient with cleft lip and palate pre operative based on the characteristic of gender has a p-value $=0.197(>0.05)$ which means it does not have a statistically significant effect on oral hygiene status. The same result is shown in the group of patients with cleft lip and palate post operative based on the characteristic of gender has a p-value $=$ $0.335(>0.05)$ which means it does not have a statistically significant effect on oral hygiene status. This caused by information about oral health maintenance obtained by male and female respondents 
coming from the same source as mass media (television) and formal counseling by health workers. ${ }^{6}$

The patients with cleft lip and palate pre operative based on their level of education has a p-value $=0.446(>0.05)$ which means it does not have a statistically significant effect on oral hygiene status. The same results are shown in the group of patients with cleft lip and palate post operative based on education level the results does not have a significant effect on oral hygiene status because it has a p-value $=0.088(>0.05)$. In this study, the level of knowledge about the importance of maintaining oral health obtained by respondents and their families was good enough, but the knowledge possessed was not responded positively to attitude and actions to maintain oral health due to the limited physical condition of the respondents.

The patients with cleft lip and palate pre operative based on economic status the results does not have have a significant effect on oral hygiene status because it has a p-value $=0.264(>0.05)$. The same results are shown in the group of patients with cleft lip and palate post operative based on economic status has a $\mathrm{p}$-value $=0.143(>0.05)$ which means it does not have a statistically significant effect on oral hygiene status. In this study, the economy condition of the respondents and the average family is good enough, means that is not too difficult to get education and health services and providing protective factors for maintaining oral health such as toothbrushes and fluoride toothpaste, but due to limited physical conditions they have respondents cause dental and oral health maintenance measures to be not optimal. ${ }^{4}$

The analysis result shows that the group of patients with cleft lip and palate pre operative had an average oral hygiene status of 2.69 while the post operative group was 2.04 with a value of $\mathrm{p}=0.062$ $(>0.05)$ which means there were no statistically significant differences. In patients with cleft lip and palate pre operatively, the presence of cleft in the oral cavity causes maintenance of oral hygiene to be less than optimal so that usually patients with this condition have poor oral hygiene. In addition, patients also usually have severe crowding which causes difficulties in maintaining oral hygiene, while in patients with cleft lip and palate post operatively, the presence of residual scar tissue as a result of the multiple surgical procedures carried out at the cleft region which in turn impairs tooth cleaning so that this can affect oral hygiene maintenance. Errors during data collection can also cause this to occur because oral hygiene status data collection is done manually so that the results obtained are very subjective and allow for occurring the errors. ${ }^{7-9}$

\section{Conclusion}

There was no difference in oral hygiene status in patients with cleft lip and palate preoperative and postoperative in Takalar Regency.

\section{Acknowledgment}

Thank you Faculty of Dentistry Hasanuddin University for the provided support and all involved in this study.

\section{Conflict of Interest}

The authors report no conflict of interest.

\section{References}

1. Anderson L, Kahnberg KE, Pogrel MA. Oral and maxillofacial surgery. Oxford, United Kingdom: Blackwell Publishing; 2010. p. 945-947.

2. Warubania SA, Bhatara $\mathrm{T}$, Widjajanegara $\mathrm{H}$, et al. Description of maternal risk factor in first trimester of pregnancy and orofacial cleft types in YPPCBL 2017. SPeSIA 2018;4: 602. (In Indonesia)

3. Pisek A, Pitiphat W, Chowcheun B. Oral health status and oral impacts on quality of life in early adolescent cleft patients. J Med Assic Thai 2014;97: S7-S9.

4. Sherlyta M, Wardani R, Susilawati S. Oral hygiene level of underdeveloped village State Elementary School students in Bandung Regency. Padjajaran J Dent 2017;29: 72-74. (In Indonesia)

5. Chohan AN, Wyne AH. Caries and oral hygiene status among a group of saudi cleft lip and palate children. Pakistan Oral Dent J 2008;28: 277.

6. Sharda J, Mathur LK, Sharda AJ. Oral health behavior and its relationship with dental caries status and periodontal status among 12-13 year old school children in udaipur india. OHDM 2013;12: 237-242.

7. Chopra A, Lakhanpal M, Rao NC, et al. Oral health in 4-6 years children with cleft lip/palate. North Am J Med Sci 2014;6: 268.

8. Nair LC, Singh AK, Prasad V, et al. Comparison of oral and dental health status in patients with or without cleft lip and palate deformities undergoing orthodontic treatment. J Cleft Lip Palate Craniofac Anomal 2016;3: 75-76.

9. Masrial, Yanwirasti, Syukur S, et al. Analysis of gene polymorphisms TGFi+ rs 1058213 to cleft lip cases with or without a non-syndrome cleft palate in Riau Malay Ethnic. J Dentomaxillofac Sci 2018;3: 32-36.

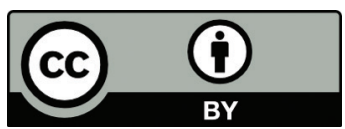

This work is licensed under a Creative Commons Attribution 